\title{
NOTES AND CORRESPONDENCE \\ A Timing Circuit for the Identification of the Cloud Top Height
}

\author{
By M. S. Unninayar \& T. Takahashi \\ Department of Meteorology, Cloud Physics Observatory, University, of Hawaii, Hilo, Hawaii 96720 \\ (Manuscript received 22 January 1973, in revised form 3 July 1973)
}

\section{Introduction}

The determination of the cloud top height and the cloud base height is important in analyzing observational results in cloud physics. The cloud top height is usually identified by the measurement of humidity in the sounding by means of a radiosonde which transmits humidity data as an independent signal occurring at fixed intervals. The cloud top is at that level where humidity decreases abruptly. Obviously, important data are lost while the humidity signal is being transmitted. The simple method presented here avoids such a loss, for the humidity is determined from the time duration of the potential gradient signal.

\section{Electric circuit}

The timing circuit was developed in order to measure continuously the electric potential gradient in warm clouds. The potential gradient signal alternates with a reference signal, which provides information on the drift of the circuitry. In this instrument, the time duration of the potential-gradient signal is a function of the humidity, and the time duration of the reference signal is a function of the temperature.

The switching circuit is basically a lowfrequency multivibrator driving a transistor with its collector loaded by the field coil of a relay which switches between signal and reference model. The circuit can be used to activate a
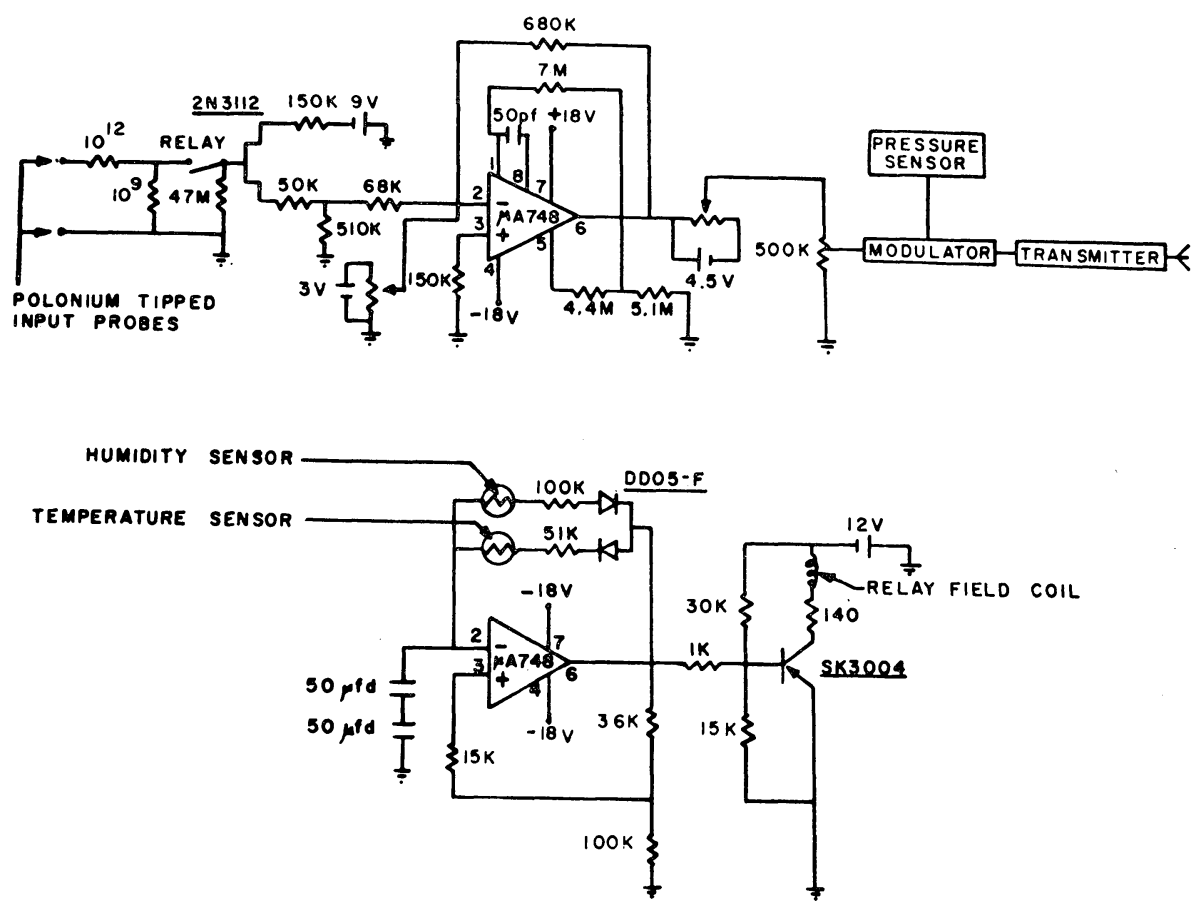

Fig. 1. Electric circuit of switching circuit with the electric circuit of the electric potential-gradient radiosonde. 
variety of relays by adjusting the current through the load impedance of the transistor. The load resistor is adjusted to $140 \Omega$ to give a load current of approximately $35-40 \mathrm{~mA}$, which is sufficient to activate the appropriate relay.

Humidity and temperature dependent timing is accomplished by using a double diode in the feedback loop of the multivibrator (Fig. 1). This isolates the charging and discharging circuit paths through the capacitor connected between the inverting input of the amplifier ( $\mu \mathrm{A} 748)$ and the ground. A U.S. Weather Bureau radiosonde thermistor and humidity sensor are connected in series in the feedback loop sections, so that the

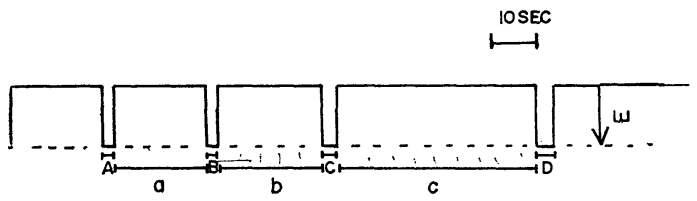

Fig. 2. Switching periods as a function of humidity and temperature. $\mathbf{E}$ shows the electric potential gradient from the referance. Switching periods for various humidities are shown in $\mathrm{a}(55 \%), \mathrm{b}(65 \%)$ and $\mathrm{c}(80 \%)$. Switching periods for various temperatures are shown in $\mathrm{A}\left(17.5^{\circ} \mathrm{C}\right), \mathrm{B}\left(20.5^{\circ}\right), \mathrm{C}$ $\left(15.8^{\circ} \mathrm{C}\right)$ and $\mathrm{D}\left(6.8^{\circ} \mathrm{C}\right)$.

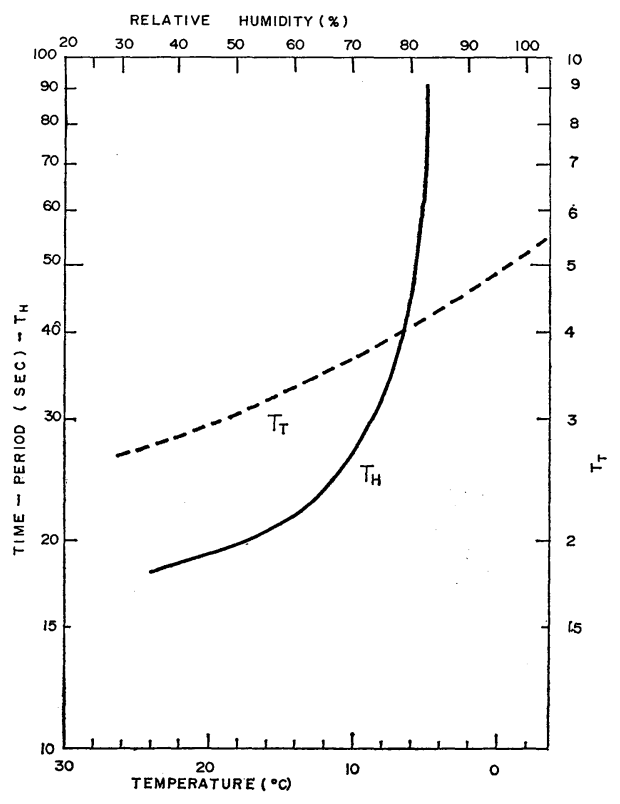

Fig. 3. Curve of switching time period with a function of humidity $\left(T_{H}\right)$ and temperature $\left(T_{T}\right)$. charging and discharging time constants are functions of the humidity and temperature.

\section{Calibration and observation}

The instrument was calibrated under laboratory controlled environmental conditions. Output samples and calibration curves are as shown in Figs. 2 and 3. The time duration of the

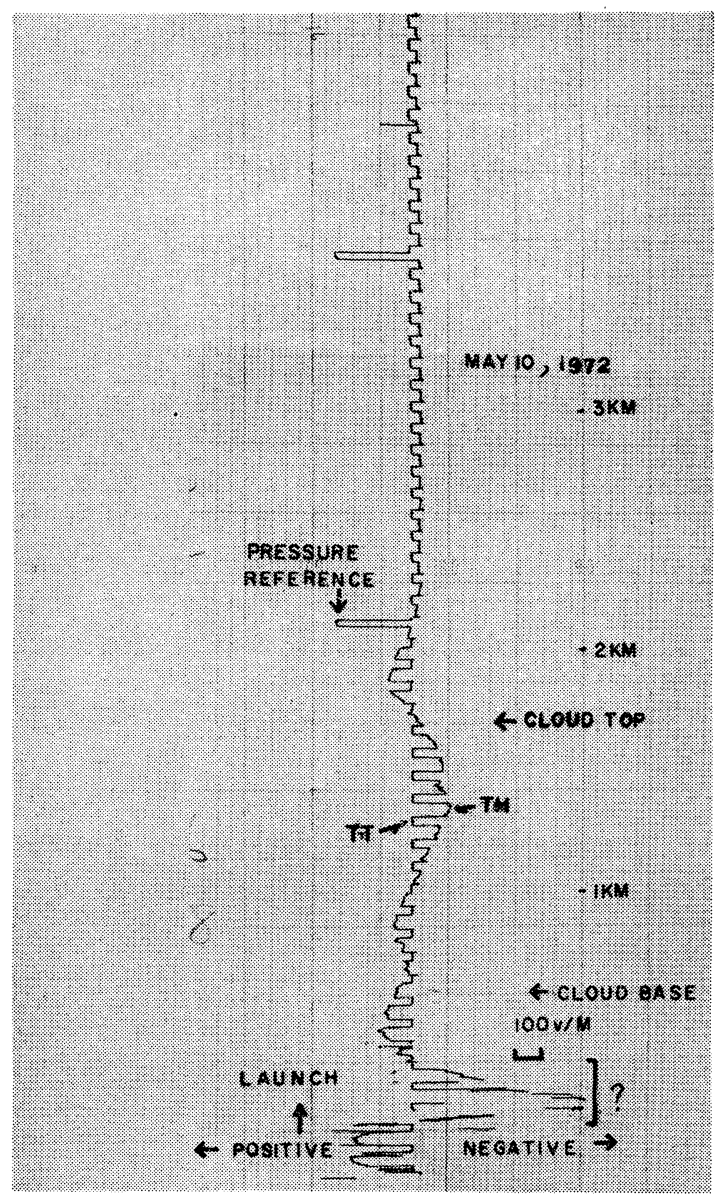

Fig. 4. Electric potential gradient in warm clouds during rain. The cloud top height is estimated where the switching time duration decreased abruptly. The referance signal occurring with temperature time duration $\left(T_{T}\right)$ is obtained by grounding the input through a $47 \mathrm{meg}-\mathrm{ohm}$. Thus the referance signal does not correspond to a true zero input condition but is offset from the true zero. The offset is determined during the calibration by connecting two probes which are set apart vertically. In this figure the electric potential gradient above the first pressure referance is zero. 
potential gradient signal varies from 19 to 91 seconds as the relative humidity increases from $44 \%$ to $82.5 \%$, and that of the reference signal varies from 2.9 to 5.2 seconds as the temperature decreases from $20.5^{\circ} \mathrm{C}$ to $-3.0^{\circ} \mathrm{C}$. The functional relationship of the reference signal time period with temperature is determined by the temperature coefficient of resistance of the thermistor used as a temperature sensor. The time duration of the potential gradient signal increases very sharply as the humidity increases above $82 \%$.

The circuit was extensively tested for performance and stability. It was subjected to temperature cycling, by placing it inside a cold room, cooling it to $-3^{\circ}$ and warming the room back to room temperature. No significant hysteresis with temperature cycling was observed. The instrument was then placed in a humidity chamber and subjected to humidity cycling with humidity ranging from $50 \%$ to $82 \%$. A slight hysteresis was observed with a $3 \%$ change due to humidity cycling. This is entirely due to surface changes on the humidity sensor and not attributable to any circuit characteristics. There was no noticeable interaction between the signal and reference time duration; i.e., the temperature time duration remained constant with humidity cycling and vice versa.

The warm cloud in a tropical area can develop to about $500 \mathrm{~m}$ above the layer where humidity drops abruptly from about $80 \%$ to $20 \%$.
Therefore, humidity change at the cloud top is very abrupt, and the humidity sensor responds with sufficient rapidity to enable the transition point, viz. the cloud top, to be estimated with fair accuracy; the humidity timing for the transition being a function of the in-cloud humidity, out-of-cloud humidity and the transition point.

A portion from an actual cloud sounding is shown in Fig. 4 on a compressed time scale. Cloud top height was estimated to be at that position where the humidity decreased abruptly (as the radiosonde was launched during rain); in this case it was estimated at $1.7 \mathrm{~km}$. The cloud-top-sensing capability of the instrument was verified by observations made from a helicopter. The instrument package was dropped with parachutes attached to it and the exact time of entry into the cloud was visually observed and noted. This time of entry corresponded to that determined from the humidity data transmitted to ground, confirming the validity of cloud top determination by this method. The accuracy was found to be around $\pm 100 \mathrm{~m}$. Cloud base height in this figure (4) was determined by visual observing when the instrument disappeared into the cloud.

In conclusion, this timing circuit method enables us to determine the cloud top height without adding another independent signal for the determination of humidity.

\title{
雲頂高度決定のための簡易スイッチ回路
}

\author{
M.S. Unninayar ・高 橋劭
}

ハワイ大学雲物理観測所, ヒロ 